\title{
Eyelid Disorders in Ophthalmology Practice: Results from a Large International Epidemiological Study in Eleven Countries
}

\author{
Serge Doan · Zbigniew Zagórski · Jorge Palmares · Meltem Yağmur • \\ Thomas Kaercher · José Manuel Benítez-Del-Castillo • Bart Van Dooren • \\ Paul Jonckheere · Peter Koch Jensen · Dmitry Yurevich Maychuk • \\ Pavlo Bezdetko
}

Received: May 13, 2020 / Published online: July 1, 2020

(C) The Author(s) 2020

\begin{abstract}
Purpose: Anecdotal evidence suggests that eyelid disorders are common, although estimates of prevalence vary. The current study determines the prevalence of eyelid disorders, meibomian gland dysfunction (MGD) and related diseases (specifically ocular surface disease) in a population of patients presenting for routine ophthalmologic consultations.
\end{abstract}

Digital Features To view digital features for this article go to https://doi.org/10.6084/m9.figshare.12436589.

S. Doan $(\varangle)$

Fondation A de Rothschild, Paris, France

e-mail: serge.doan@noos.fr

Z. Zagórski

Eye Surgery Center, Nalenchuv, Poland

J. Palmares

Hospital Lusíadas, Porto, Portugal

M. Yă̆mur

The Faculty of Medicine Balcalı Hospital, Cukurova

University, Adana, Turkey

T. Kaercher

Augenarztpraxis, Dossenheimer Landstr, Heidelberg, Germany

J. M. Benítez-Del-Castillo

Unidad de Superficie e Inflamación Ocular, Servicio de Oftalmología, Instituto de Investigación

Sanitaria, Hospital Clínico Universitario San Carlos,

Madrid, Spain
Methods: This cross-sectional epidemiologic survey evaluated patients presenting for routine ophthalmic visits. During the consultation an ophthalmologist completed a questionnaire, and each patient underwent an ophthalmic examination and completed a quality of life questionnaire.

Results: Three hundred forty-nine ophthalmologists, recruited from 11 countries, provided data on 6525 patients. Patients were predominantly females (61.6\%). The mean age of the study population was $57.0 \pm 17.6$ years. Eyelid disorders were diagnosed in 5109 (78.3\%) patients and were statistically associated with:

B. Van Dooren

Erasmus Medical Center, Rotterdam, The Netherlands

P. Jonckheere

Oogkliniek Deurne, Antwerp, Belgium

P. K. Jensen

Roskilde Hospital, Copenhagen University, Copenhagen, Denmark

D. Y. Maychuk

Svyatoslav N. Fyodorov State Institution Eye Microsurgery Complex, Moscow, Russia

P. Bezdetko

Kharkiv National Medical University, Kharkiv, Ukraine 
atopic dermatitis, seborrheic dermatitis, dry eye, age-related macular degeneration, diabetes, cataract, allergy and MGD $(P<0.05$, all associations). Eyelid abnormalities were identified in $59.6 \%$ of patients; conjunctival or corneal abnormalities were observed in $64.9 \%$ and $28.1 \%$ of patients, respectively. MGD was diagnosed in $54.3 \%$ patients and was statistically significantly associated with the presence of eyelid disorders and eyelid margin abnormalities $(P<0.001$, both comparisons). Dry eye was diagnosed in $61.8 \%$ of patients. Concurrent dry eye and MGD were present in $67.6 \%$ of patients. Most patients reported some degree of impaired vision and daily/work activities related to dry eye. Impact on contact lens usage, emotions and quality of sleep was also reported. The effects on daily life were associated with the presence of MGD.

Conclusion: In conclusion, eyelid disorders were highly prevalent in this 'real-world' population of patients from ophthalmology clinics. Routine ophthalmologic consultations provide an opportunity to improve patient quality of life and to modify topical therapy in patients who may be predisposed to eyelid disorders.

Keywords: Blepharitis; Dry eye; Eyelid disorders; Meibomian gland disorder; Ocular surface disease

\section{Key Summary Points}

\section{Why carry out this study?}

Anecdotal evidence and clinical experience suggest that eyelid disorders are common in daily clinical practice. However, multicenter international studies of prevalence are rare.

This study evaluated the prevalence of eyelid disorders in a 'real-world' European multicenter trial.

\section{What was learned from the study?}

Among patients present for routine ophthalmic visits, the prevalence of MGD was $54 \%$ (data).
The high prevalence of MGD and associated ocular surface disorders indicates that these disorders may be underdiagnosed and the majority of routine ophthalmic patients may require assessment for ocular surface disease.

Timely treatment of ocular surface disease and eyelid disorders may improve compliance with topical therapy for other ophthalmic conditions.

\section{INTRODUCTION}

The etiology of dry eye is multifactorial and involves a dysfunctional lacrimal system [1-4]. Meibomian gland dysfunction (MGD) is the most common cause of dry eye disease, and the interactions between these two conditions have been described as a 'vicious cycle' that causes tear film instability (due to MGD) leading to hyperosmolarity and inflammation that is characteristic of dry eye disease, which in turn promotes further MGD [5]. The lipid and protein secretions from the meibomian glands are critical in maintaining the tear film by mitigating evaporation and dryness [6]. The relationship between MGD and dry eye has been well documented in the literature [3, 4].

Dry eye can significantly impair quality of life by interfering with daily living activities and work [7, 8]. Dry eye represents a significant proportion of any ophthalmic practice, yet the real prevalence remains ambiguous because of methodologic techniques $[9,10]$. Similarly, MGD appears to be a common ophthalmic condition. The International Workshop on MGD reported a wide range of prevalence from population-based studies depending on methodology and ethnicity [11]. Studies performed in clinical ophthalmic settings generally reported a higher prevalence [11].

The objective of the present multicenter, international study is to determine the prevalence of eyelid disorders in a representative population of patients presenting for routine ophthalmic consultations. 


\section{METHODS}

\section{Study Design}

A cross-sectional epidemiologic survey was performed on patients presenting for routine ophthalmologic consultations at clinics or hospitals in Belgium, Denmark, France, Germany, The Netherlands, Poland, Portugal, Russia, Spain, Turkey, and Ukraine.

\section{Subjects}

Participating ophthalmologists were required to recruit at least ten consecutive patients presenting to their clinic regardless of the reason for the consultation. Adult patients aged 18-99 years were included in this study. There were no specific exclusion criteria other than inability or unwillingness to give informed consent.

\section{Recruitment of Investigators}

Ophthalmologists were identified from national databases and the numbers included per country adjusted to maintain proportionality. The first 349 qualifying ophthalmologists who agreed to participate in the study were selected to recruit patients.

\section{Study Setting}

The study was conducted in the context of a routine ophthalmic patient visit.

\section{Ethical Considerations}

The guidelines of Good Epidemiological Practice were followed, and this study conformed to the principles of the Declaration of Helsinki [12]. The International Conference of Harmonization ( $\mathrm{ICH}$ ) rules were not applicable as no patient interventions or management was performed specifically for this study.

Approval from local or national ethics committees was obtained according to the regulations in each country [France: Comité consultatif sur le traitement de l'information en matière de recherche (C.C.T.I.R.S.); Ukraine: Ethics Committees at Medical Centre "Eurozir"
(Zaporizhzya), at LLC "Vzgliad" MC" (Dnipropetrovsk), at Pyrogov Vinnytsya Regional Clinical Hospital (Vinnytsya), at the Centre of Modern Ophthalmology "Your Vision" (Chernivtsi), at LLC "Polymed Zakhid" (Lviv), at PI "Regional Clinical Hospital-Centre of Emergency Medical Care and Disaster Medicine"* (Kharkiv), at MI "City Polyclinic No. 29" (Odessa); Poland: Komiska Etyki Lubelska Izba Lekarska (Lublin); Spain: Comité ético de investigación clínica (Madrid); Belgium: Comité Local d'Ethique Hospitalier CHU Saint-Pierre (Brussels); Russia: Independent Interdisciplinary Committee for the Ethical Examination of Clinical Research (Moscow); Turkey: Ministry of Health (Türkiye Cumhuriyeti Sağlık Bakanlı̆ı); The Netherlands: not subject to Medical Research Involving Human Subjects Act and ethics review (Rotterdam); German: Ethics Committees of the German Medical Association 'Landesärztekammer' (Baden-Württemberg, Bayern, Brandenburg, Hessen, Rheinland-Pfalz, Sachsen) and 'Ärztekammer' (Berlin, Bremen, Hamburg, Niedersachsen, Nordrhein, Saarland, Schleswig-Holstein, Westfalen-Lippe). There was no regulatory process required for other countries because this was an observational study.] This study required no additional investigations, outside of those normally performed for a routine ophthalmologic consultation or required by clinical findings during the consultation.

Prior to data collection, all patients underwent a thorough informed consent procedure that explained the nature and purpose of the study and the use of their data. Approval from data protection organizations was not required because no direct or indirect personally identifiable data were collected.

\section{Primary Objective}

The primary objective of the study was to determine the prevalence of eyelid disorders in a population of general ophthalmology patients. 


\section{Secondary Objectives}

Secondary objectives were to evaluate for associations between eyelid disorders and ocular surface pathology, to assess the impact of eyelid disorders on patient quality of life and to determine the current strategy among ophthalmologists for treating eyelid disorders in routine practice.

\section{Procedure}

During the course of ophthalmic consultation, the investigator completed a questionnaire for each patient enrolled in the study. An ocular surface examination was also performed. Tests such as Schirmer's test, tear break-up time and slit-lamp examination were performed as clinically warranted. Data were collected on the impact of ocular symptoms on the daily living activities of the patients. The intended management plan was noted for any pathology identified during the consultation.

\section{Clinical Examinations}

\section{Eyelid and Meibomian Gland Examination}

A patient was diagnosed with an eyelid disorder if at least one of the following clinical signs were present: abnormal position of eyelids (entropion, ectropion, floppy eyelids); abnormal eyelashes (sparse, trichiasis, distichiasis, madarosis, cylindrical dandruff); abnormal eyelid margin (desquamation and crusting, telangiectasia, thickening, irregularities, whitish foam, fatty secretions, pigmentation, inflammation/swelling, meibomian gland obstruction); unclear secretions with pressure was applied to the meibomian gland (cloudy secretion, toothpaste-type secretion, secretion not expressed); miscellaneous abnormalities such as stye, chalazion and concretions.

\section{Ocular Surface Examination}

The ocular surface was examined, and a slitlamp examination with staining was performed if clinically required. Investigators specifically noted the presence of hyperemia, follicles, papillae and concretions. Corneal examination was performed with specific reference to ulceration, filaments, superficial punctate keratitis and pannus.

\section{Schirmer's Test and Tear Break-Up Time}

Schirmer's test and tear break-up time were performed according to the clinician's normal practice and clinical need. Schirmer's test was scored as normal or abnormal $(<10 \mathrm{~mm}$ in $5 \mathrm{~min})$. Tear break-up time was scored as normal or abnormal $(<10 \mathrm{~s})$.

\section{Symptoms}

The questionnaire included specific queries on the presence of red eye; burning/stinging sensation; irritation with foreign body sensation; itching; tearing in the morning or during the day; dry eye sensation; sensitivity to light; dry, rough eyelid skin; discomfort on opening and closing eyelids; blurred vision. These signs and symptoms were rated on a 4-point scale as follows: $0=$ none; $1=$ present but not disturbing; 2 = disturbing; 3 = very disturbing.

Questionnaire items also recorded the degree of impact of symptoms on vision, daily activities and work, leisure, use of contact lenses, emotions and sleep. The degree of impact was scored as slight, moderate or severe.

\section{Statistical Methods}

Sample size calculations estimated an expected prevalence of eyelid disorders of $60-70 \%$ and a target precision of about $4 \%$. Power calculations suggested that 539 patients were required for the primary variable. However, ten classes of ocular history were being considered in this study (rosacea, atopic dermatitis, seborrheic dermatitis, dry eye, age-related macular degeneration, glaucoma, diabetes, cataract, allergy and MGD); hence, a patient sample size of approximately 5390 was planned. Each investigator was required to enroll 10 consecutive patients, and a $20 \%$ rate of inactivity or underenrollment by investigators led to a target of recruiting 647 ophthalmologists.

Statistical associations were evaluated for the incidence of MGD and the presence of eyelid disorders, clinical signs of eyelid disorders and 
ocular surface disorders. The chi-square test or Fischer's exact test were used as appropriate. $P<$ 0.05 was considered statistically significant.

\section{RESULTS}

\section{Patient Population}

A total of 349 investigators were recruited, and 6660 patients were enrolled. Data from 6525 patients were used in the final analysis. One hundred thirty-five patients did not meet the inclusion criteria and were excluded from the analysis.

The largest numbers of ophthalmologists and patients were recruited in Poland and Spain. The majority of ophthalmologists involved in the study described themselves as general ophthalmologists. The mean patient age was $57.0 \pm 17.6$ years, and $61.6 \%$ of patients were female (Table 1 ).

\section{Ocular History}

Prior ocular history was reported in $79.2 \%$ of patients and included dry eye in $30 \%$ of patients, followed by $27.2 \%$ of patients with cataract, $18.1 \%$ with ocular manifestations of diabetes, $16.3 \%$ with glaucoma, $15.1 \%$ with

Table 1 Demographic Characteristics of Patients Presenting for a Routine Ophthalmic Visit

Age (years) $(N=6335$ patients $)$

$\begin{array}{ll}\text { Mean } \pm \text { SD } & 57.0 \pm 17.6 \\ \text { Min; max } & 18 ; 99\end{array}$

Gender ( $N=6292$ patients)

$\begin{array}{lll}\text { Male } & n(\%) & 2414(38.4 \%) \\ \text { Female } & n(\%) & 3878(61.6 \%)\end{array}$

Contact lenses wearers ( $N=5753$ patients)

\begin{tabular}{lll} 
Yes & $n(\%)$ & $645(11.2 \%)$ \\
No & $n(\%)$ & $5108(88.8 \%)$ \\
\hline
\end{tabular}

$N$ number of patients, $S D$ standard deviation
MGD, $12.7 \%$ with allergy and $10.9 \%$ with agerelated macular degeneration.

\section{Prevalence of Eyelid Disorders}

Eyelid disorders were present in 78.3\% [95\% confidence interval (CI) 77.3-79.3\%] of patients. There was a statistically significant association between eyelid disorders and rosacea, atopic dermatitis, seborrheic dermatitis, dry eye, age-related macular degeneration, diabetes, cataract, allergy and MGD $(P<0.02$, Fischer's exact test or chi-squared test, all associations).

Eyelid disorders were statistically significantly associated with the presence of the following subjective symptoms: red eye, burning/ stinging sensation, irritation with foreign body sensation, itching; tearing in the morning or during the day, sensation of dry eye, sensitivity to light, dry, rough eyelid skin, discomfort on opening and closing eyelids and blurred vision $(P<0.001$, Fischer's exact test or chi-squared test, all associations). Dry and rough eyelid skin was the most common subjective symptom associated with the presence of eyelid disorders (93\%). Several other subjective symptoms were associated with eyelid disorders at rates $>80 \%$.

\section{External Appearance of Eyelids}

Examination indicated $50 \%$ of patients with abnormal appearance of the periocular skin, predominantly redness (19.3\% of patients) and oily $(10.9 \%$ of patients) or dry skin $(13.1 \%$ of patients); $12.3 \%$ of patients had an abnormal lid position, such as floppy eyelids $(8.5 \%$ of patients), ectropion $(2.5 \%$ of patients $)$ or entropion (1.3\% of patients). Twenty-seven percent of patients had an abnormal appearance of the eyelashes.

\section{Eyelid Margin and Meibomian Gland Examination}

The eyelid margin was abnormal in $59.6 \%$ of patients. Lid margin abnormalities included, telangiectasia in $36.9 \%$ of patients, thickening in $37.1 \%$ and meibomian gland obstruction in $31.3 \%$. Pressure on the glands produced cloudy 
secretion in $26.1 \%$ of patients, toothpaste-type secretions in $8.7 \%$ of patients and no secretions in $26.1 \%$ of patients. Stye, chalazion and concretions were noted in $4-5 \%$ of patients.

\section{Ocular Surface Examination}

Abnormal conjunctiva was noted in $64.9 \%$ of patients (Table 3). Hyperaemia was the most common conjunctival abnormality (87.8\%) (Table 3); $28.1 \%$ of patients had corneal abnormalities (Table 3). Superficial punctate keratitis was the most common corneal abnormality (Table 3). An abnormal tear break-up time was noted in $50.5 \%$ of patients, and an abnormal Schirmer's test was noted in $37.0 \%$ (Table 2).

\section{Overall Diagnosis}

Dry eye was diagnosed in $61.8 \%$ of patients. Ocular surface disorders such as allergic conjunctivitis and infectious conjunctivitis were diagnosed in $9.9 \%$ and $4 \%$ of patients, respectively. The majority (74.6\%) of patients with an abnormal tear break-up time had concurrent MGD.

MGD was diagnosed in $54.3 \%$ of patients. Of these patients, $37.6 \%$ had hyposecretory MGD, $36.9 \%$ had obstructive MGD and 37.2\% had hypersecretory MGD. Hyposecretory MGD was predominantly primary in nature $(74 . \%)$ as were cicatricial (76.6\%) and non-cicatricial (60\%) MGD. Secondary cases of hypo- and hypersecretory MGD were most frequently due to seborrheic dermatitis, acne rosacea or atopy. Secondary cases of cicatricial obstructive MGD were most commonly due to atopy, ocular pemphigoid or trachoma.

The diagnosis of MGD was statistically significantly associated with eyelid disorders, eyelid margin abnormality and conjunctival hyperaemia ( $P<0.001$, all associations). MGD was not associated with superficial punctate keratitis. There was a statistically significant association between MGD and dry eye $(P<0.001)$. Among patients diagnosed with either MGD or dry eye, $67.6 \%$ had concurrent MGD and dry eye (Table 3).
Table 2 Ocular surface examination of patients presenting for a routine ophthalmic visit

\begin{tabular}{|c|c|}
\hline Parameter & Value \\
\hline Conjunctival examination & $N=6473$ \\
\hline Normal & $35.1 \%$ \\
\hline Abnormal & $64.9 \%$ \\
\hline Type of conjunctival abnormality & $N=4201$ \\
\hline Papillae & $13.2 \%$ \\
\hline Conjunctival hyperemia & $87.8 \%$ \\
\hline Fluorescein staining & $14.0 \%$ \\
\hline Follicles & $13.1 \%$ \\
\hline Concretions & $8.0 \%$ \\
\hline Corneal examination & $N=6405$ \\
\hline Normal & $71.9 \%$ \\
\hline Abnormal & $28.1 \%$ \\
\hline Type of corneal abnormality & $N=1801$ \\
\hline Superficial punctate keratitis (fluorescein) & $81.0 \%$ \\
\hline Ulceration & $6.2 \%$ \\
\hline Pannus & $9.8 \%$ \\
\hline Filaments & $14.5 \%$ \\
\hline \multicolumn{2}{|l|}{ Tear film examination } \\
\hline Break-up time & $N=5527$ \\
\hline Normal & $49.5 \%$ \\
\hline Abnormal $(<10 s)$ & $50.5 \%$ \\
\hline Schirmer's test & $N=4758$ \\
\hline Normal & $63.0 \%$ \\
\hline Abnormal $(<10 \mathrm{~mm}$ in $5 \mathrm{~min})$ & $37.0 \%$ \\
\hline
\end{tabular}

Some patients had concurrent conjunctival or corneal abnormalities

\section{Patient-Reported Incidence and Severity of Dry Eye Symptoms}

Figure 1 presents the patient-reported severity of dry eye symptoms. Forty percent of patients found the burning/stinging sensation disturbing or very disturbing (Fig. 1). Foreign body 
Table 3 Comparison of the proportion of meibomian gland dysfunction in dry eye patients

\begin{tabular}{lll}
\hline Dry eye & MGD & \\
\cline { 2 - 3 } & Yes $(\boldsymbol{n}=\mathbf{2 9 6 8 )}(\%)$ & No $(\boldsymbol{n}=\mathbf{2 6 3 3})(\%)$ \\
\hline Yes $(n=3360)$ & 67.6 & 32.4 \\
No $(n=2241)$ & 32.8 & 67.2 \\
\hline
\end{tabular}

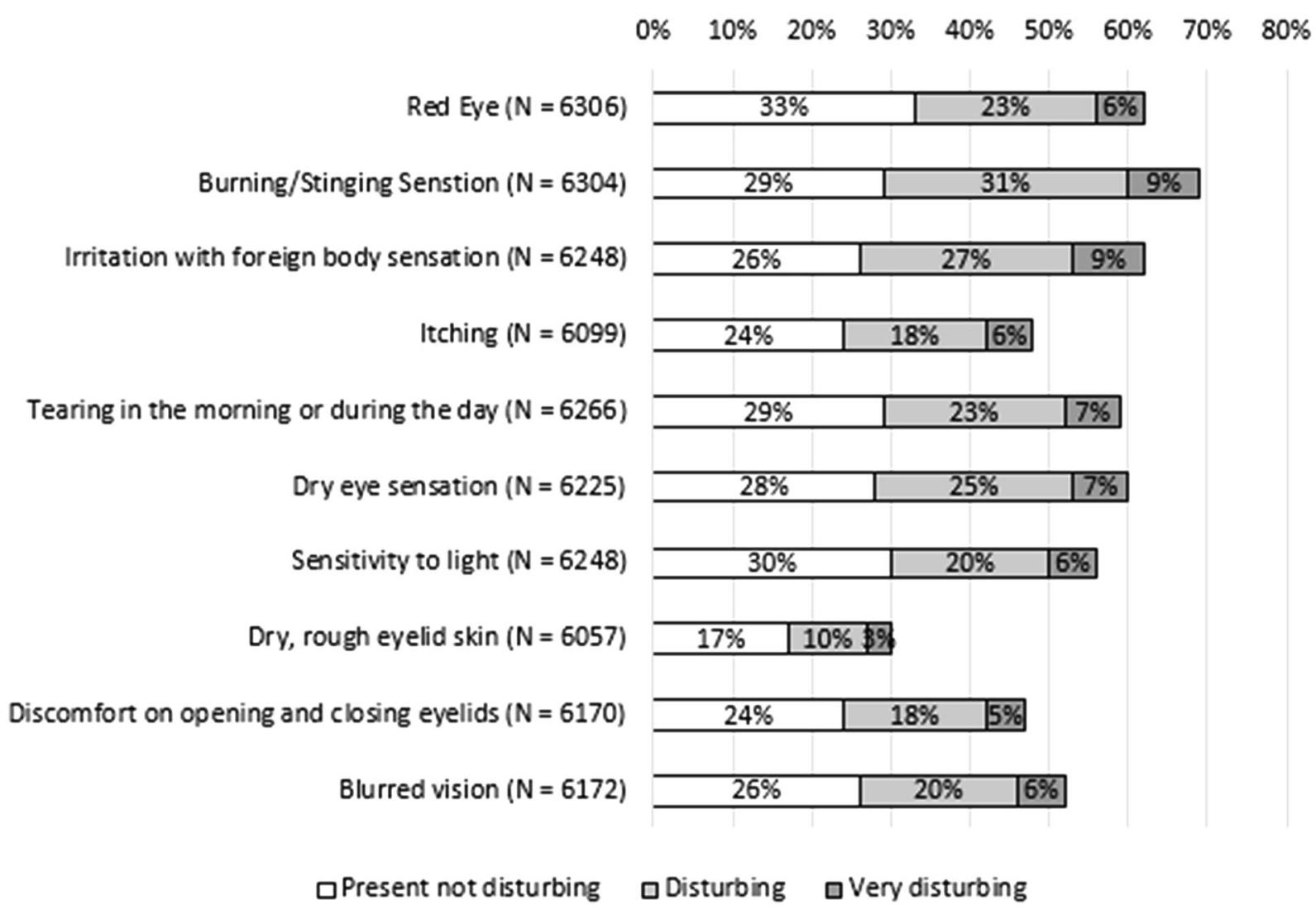

Fig. 1 Prevalence and severity of dry eye symptoms among patients presenting for a routine ophthalmic visit. Patients were queried regarding their experience of each symptom

sensation, sensation of dry eye and tearing were reported as disturbing or very disturbing in $36.6 \%, 32.7 \%$ and $30.1 \%$ of patients, respectively.

\section{Impact of Eyelid Disorders on Daily Life}

Figure 2 presents the patient-reported impact of lid disorders on daily life activities. Vision was and asked to rate them on a 3-point scale as follows: $0=$ none, $1=$ present but not disturbing, $2=$ disturbing, $3=$ very disturbing

impaired in more than half of all patients, as were daily activities and work (Fig. 2). Approximately $20 \%$ of patients had slight to strongly impaired emotion and or sleep (Fig. 2). Impacts on all domains were statistically significantly associated with the presence of MGD $(P<0.001$, all associations). Among contact lens wearers, $8.6 \%$ had to remove them because of strong impairment (indicating the significant impact of eyelid disorders on the quality of life). 
- Strong Impairment

$\square$ Slight Impairment $\square$ Moderate impairment

$\square$ No Change

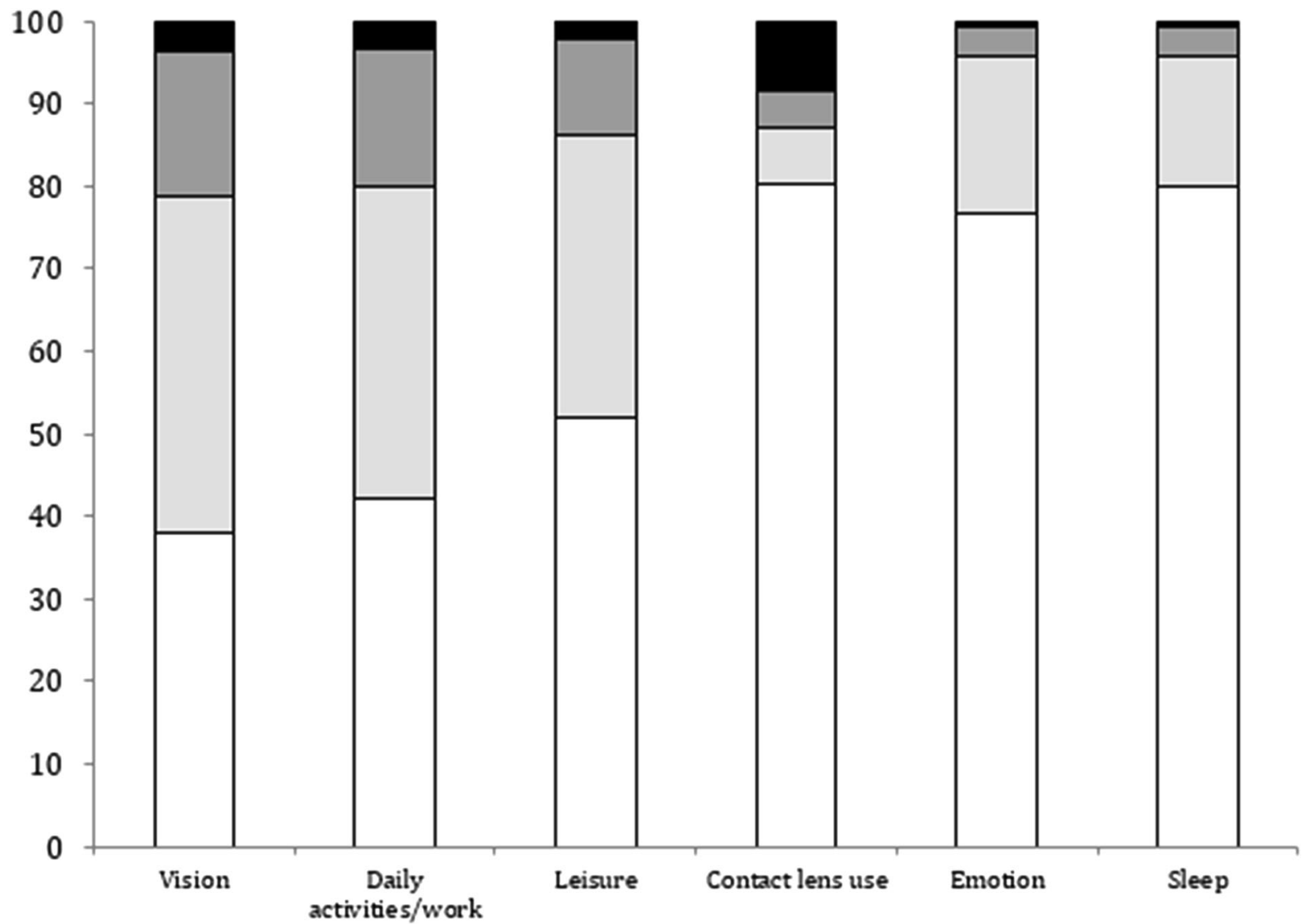

Fig. 2 Impact of eyelid disorders on daily life. Patients were questioned about the impact of eyelid disorders on their various aspects of daily life activities and the degree of

\section{Treatment of Eyelid Disorder}

Tear substitutes were the most frequently prescribed drugs (77.4\%). The most common prescriptions were viscous solutions or a combination of viscous solution and another type of eye drop. The mean number of instillations was $4.8 \pm 2.6$ per day. A prescription for topical lubricants was statistically significantly associated with a diagnosis of dry eye and MGD (both $P<0.001$ ). Eyelid hygiene recommendations included warming for $40.9 \%$ of patients with eyelid disorder, eyelid cleansing for $59.2 \%$ and ocular massage for $44.8 \%$ of patients. impairment of each activity (slight, moderate or severe). $N=4859$ patients with eyelid disorders

Omega-3 fatty acids and vitamins were recommended for $81.1 \%$ and $62.2 \%$ of patients, respectively, who were given dietary advice. Nutritional recommendation (enhanced consumption of omega-3 fatty acids and vitamins) was proposed for the majority of patients regardless of their diagnosis.

\section{DISCUSSION}

The outcomes of this multicenter European study indicate a high prevalence of dry eye and eyelid disorders. Regional prevalence data are 
important because of the widely varying ranges reported in the literature [11]. For example, prevalence of MGD has been reported as $<10 \%$ in Caucasians to $>60 \%$ in Japanese and Chinese populations [11]. Hence, the geographic area likely plays a role in the prevalence of dry eye and MGD. The prevalence of MGD in the current study (54\%) was higher than that reported in a similar study of 120 ophthalmologists [13]. Lemp and colleagues estimated that $37 \%$ of their patients presented with some form of blepharitis, and dry eye was the most common reason that patients sought treatment [13]. Hom and colleagues used similar methods to the current study and reported a prevalence of $39 \%$ for MGD [14]. The differences in size of the study sample and the geographic locale may explain the difference in prevalence between our study and previous studies [13, 14].

Population-based epidemiologic studies have reported prevalences of dry eye up to $34 \%$ based on geographic locale [15]. It is not surprising that the prevalence of dry eye in a population presenting for ophthalmologic consultation is higher than that in the population at large. Patients with constant signs and symptoms due to dry eye are more likely to self-select to eye clinics.

We believe that the prevalence of dry eye is likely to increase over time because of demographic pressures from an aging population and environmental and lifestyle changes (e.g., airconditioning, pollution and increased use of digital devices). In the current study almost $78.3 \%$ of all patients presented with some type of eyelid disorder, and $>50 \%$ were diagnosed with MGD. Additionally, 50.5\% of patients had an abnormal tear break-up time. Abnormalities of the eyelid, cornea and conjunctiva were also common. The presence of MGD was statistically significantly associated with eyelid disorders, eyelid margin abnormalities and conjunctival hyperaemia $(P<0.05)$.

The patient survey from the current study indicates that eyelid disorders have a statistically significant impact on patient-related quality of life, particularly in terms of impairment in vision and daily activities/work. Additionally, impacts were reported on mood and quality of sleep. The impact of dry eye on patient psychology may be warranted in future studies as an association between psychologic stress and dry eye has been previously reported $[16,17]$. Studies of medical students and paramedics indicate that increased stress resulted in a greater risk of dry eye disease [16, 17].

Caution is urged in generalizing these results to the population at large. Patients presenting to an ophthalmologist are likely to be at a higher risk of dry eye and eyelid disorders. Some may be proactively seeking consultation for these conditions. Others may receive a diagnosis of dry eye/eyelid disorders in addition to the diagnosis from their presenting complaint. For example, management of glaucoma represents a considerable proportion of a general ophthalmologist's workload, and glaucoma patients are known to have a greater risk for ocular surface disorders $[18,19]$. Glaucoma patients and other general ophthalmology patients are more likely than the general population to be using topical medications, many of which contain preservatives that are toxic to the ocular surface $[20,21]$. Our subjective clinical impression is that glaucoma patients on topical therapy often complain of stinging and burning on instillation of anti-glaucoma medications. Aggressive treatment of a suboptimal ocular surface in these patients may increase patient compliance. Hence, although the outcomes of the current study are likely valid for a population of patients presenting to a general ophthalmology clinic, they may not be indicative of the general population. Notably, the outcomes of the current study do not indicate a significant association between having glaucoma and eyelid disorders, likely because of poor generalizability to the population at large.

Dry eye, MGD and eyelid abnormalities form a constellation of associated disorders that are likely to increase because of several factors. The prevalence of dry eye and glaucoma increases in older populations $[22,23]$. The prevalence of type 2 diabetes is also age-related and associated with a higher risk of dry eye [24, 25]. Lid laxity due to floppy eyelid syndrome or due to surgery is associated with evaporative dry eye $[26,27]$. Poor lid apposition results in ocular surface dessication [26]. Floppy eyelid syndrome is associated with obesity, and given the 
increasing incidence of obesity, there will like a concomitant increase in the incidence of floppy eyelid syndrome and dry eye $[26,28]$.

There are some limitations to this study including those inherent to a cross-section study design. This study design precludes any causal inferences between the associations reported here as the order of the variables and disease cannot be established (e.g., eyelid disorder or MGD or vice versa). Additionally, some major factors associated with eyelid disorders were not evaluated in this study. Individuals who use digital display terminals for long periods or those who work in a dusty environment are at greater risk for dry eye [7, 29]. For example, a significant decrease in tear film break-up time was reported among patients subjected to airborne dust in a climate chamber [29].

\section{CONCLUSION}

In summary, this study confirms a high prevalence of dry eye, MGD and associated ocular surface disorders in a population of patients presenting for a routine ophthalmologic assessment. However, the prevalence in this population is likely to be higher than in the general population. The findings of this study suggest that these disorders are underdiagnosed, and the majority (perhaps all) of patients require assessment for dry eye, MGD and ocular surface disease. Timely diagnosis and appropriate treatment of eyelid disorders and dry eye present an opportunity to improve patient-related quality of life and perhaps to improve their adherence to topical treatment of other ophthalmic conditions.

\section{ACKNOWLEDGEMENTS}

Funding. Laboratoires Théa paid a CRO to conduct the study, for data management and for statistical analysis. Thea Laboratories paid the Rapid Service Fee for the journal.

Medical Writing, Editorial and Other Assistance. John Stolz of JSI Medical
Communications Ltd. provided medical writing assistance, funded by Laboratoires Théa.

Authorship. All named authors meet the International Committee of Medical Journal Editors (ICMJE) criteria for authorship for this article, take responsibility for the integrity of the work as a whole, and have given their approval for this version to be published.

Prior Presentation. Some of the contents of this publication have been presented at the European Association for Vision and Eye Research Congress 2019, Nice, France.

Disclosures. Serge Doan is a consultant for Alcon, Allergan, Bausch \& Lomb, Horus, Johnson and Johnson, Santen, Laboratoires Théa. All authors (Serge Doan, Zbigniew Zagórski, Jorge Palmares, Meltem Yağmur, Thomas Kaercher, José Manuel Benitez del Castillo, Bart Van Dooren, Paul Jonckheere, Peter Koch Jensen, Dmitry Yurevich Maychuk, Pavlo Bezdetko) received fees from Laboratoires Théa to participate and recruit patients.

Compliance with Ethics Guidelines. The guidelines of Good Epidemiological Practice were followed, and this study conformed to the principles of the Declaration of Helsinki. Approval from local or national ethics committees was obtained according to the regulations in each country [France: Comité consultatif sur le traitement de l'information en matière de recherche (C.C.T.I.R.S.); Ukraine: Ethics Committees at Medical Centre "Eurozir" (Zaporizhzya), at LLC "Vzgliad" MC" (Dnipropetrovsk), at Pyrogov Vinnytsya Regional Clinical Hospital (Vinnytsya), at the Centre of Modern Ophthalmology "Your Vision" (Chernivtsi), at LLC "Polymed Zakhid" (Lviv), at PI "Regional Clinical Hospital-Centre of Emergency Medical Care and Disaster Medicine"* (Kharkiv), at MI "City Polyclinic No. 29" (Odessa); Poland: Komiska Etyki Lubelska Izba Lekarska (Lublin); Spain: Comité ético de investigación clínica (Madrid); Belgium: Comité Local d'Ethique Hospitalier CHU Saint-Pierre (Brussels); Russia: Independent Interdisciplinary Committee for the Ethical Examination of 
Clinical Research (Moscow); Turkey: Ministry of Health (Türkiye Cumhuriyeti Sağlık Bakanlığı); The Netherlands: not subject to Medical Research Involving Human Subjects Act and ethics review (Rotterdam); German: Ethics Committees of the German Medical Association 'Landesärztekammer' (Baden-Württemberg, Bayern, Brandenburg, Hessen, Rheinland-Pfalz, Sachsen) and 'Ärztekammer' (Berlin, Bremen, Hamburg, Niedersachsen, Nordrhein, Saarland, Schleswig-Holstein, Westfalen-Lippe). There was no regulatory process required for other countries because this was an observational study]. Prior to data collection, all patients underwent a thorough inform consent procedure that explained the nature and purpose of the study and the use of their data. Approval from data protection organizations was not required because no direct or indirect personally identifiable data were collected.

Data Availability. The datasets during and/ or analyzed during the current study are not publicly available because the ethics committees did not agree to broad sharing of the data beyond the scope of this study.

Open Access. This article is licensed under a Creative Commons Attribution-NonCommercial 4.0 International License, which permits any non-commercial use, sharing, adaptation, distribution and reproduction in any medium or format, as long as you give appropriate credit to the original author(s) and the source, provide a link to the Creative Commons licence, and indicate if changes were made. The images or other third party material in this article are included in the article's Creative Commons licence, unless indicated otherwise in a credit line to the material. If material is not included in the article's Creative Commons licence and your intended use is not permitted by statutory regulation or exceeds the permitted use, you will need to obtain permission directly from the copyright holder. To view a copy of this licence, visit http://creativecommons.org/licenses/by$\mathrm{nc} / 4.0 /$.

\section{REFERENCES}

1. The definition and classification of dry eye disease: Report of the Definition and Classification Subcommittee of the International Dry Eye Workshop (2007) Ocul Surf. 2007;5:75-92.

2. Borchman D, Foulks GN, Yappert MC, et al. Human meibum lipid conformation and thermodynamic changes with meibomian gland dysfunction. Invest Ophthalmol Vis Sci. 2011;52(6):3805-17.

3. Baudouin C. A new approach for better comprehension of diseases of the ocular surface. J Fr Ophtalmol. 2007;30(3):239-46.

4. Knop E, Knop N, Millar T, Obata H, Sullivan DA. The international workshop on meibomian gland dysfunction: report of the subcommittee on anatomy, physiology, and pathophysiology of the meibomian gland. Invest Ophthalmol Vis Sci. 2011;52(4):1938-78.

5. Baudouin C, Messmer EM, Aragona P, Geerling G, Akova YA, Benítez-Del-Castillo J, Boboridis KG, Merayo-Lloves J, Rolando M, Labetoulle M. Revisiting the vicious circle of dry eye disease: a focus on the pathophysiology of meibomian gland dysfunction. Br J Ophthalmol. 2016;100(3):300-6.

6. Butovich IA. The Meibomian puzzle: combining pieces together. Prog Retin EyeRes. 2009;28(6): 483-98.

7. Barabino S, Labetoulle M, Rolando M, Messmer EM. Understanding symptoms and quality of life in patients with dry eye syndrome. Ocul Surf. 2016;S1542-0124(16):30039-8.

8. McDonald M, Patel DA, Keith MS, Snedecor SJ. Economic and humanistic burden of dry eye disease in Europe, North America, and Asia: a Systematic Literature Review. Ocul Surf. 2016;2:144-67.

9. O'Brien PD, Collum LM. Dry eye: diagnosis and current treatment strategies. Curr Allergy Asthma Rep. 2004;4(4):314-9.

10. Bartlett JD, Keith MS, Sudharshan L, Snedecor SJ. Associations between signs and symptoms of dry eye disease: a systematic review. Clin Ophthalmol. 2015;9:1719-30.

11. Schaumberg DA, Nichols JJ, Papas EB, Tong L, Uchino M, Nichols KK. The international workshop on meibomian gland dysfunction: report of the subcommittee on the epidemiology of, and associated risk factors for. MGD. Invest Ophthalmol Vis Sci. 2011;52(4):1994-2005. 
12. Good Epidemiological Practice (GEP). International Epidemiological Association. 2007. http://ieaweb. org/good-epidemiological-practice-gep/. Accessed 2016.

13. Lemp MA, Nichols KK. Blepharitis in the United States 2009: a survey-based perspective on prevalence and treatment. Ocul Surf. 2009;7(2 Suppl): S1-14.

14. Hom MM, Martinson JR, Knapp LL, Paugh JR. Prevalence of Meibomian gland dysfunction. Optom Vis Sci. 1990;67(9):710-2.

15. The epidemiology of dry eye disease. Report of the Epidemiology Subcommittee of the International Dry Eye WorkShop (2007). Ocul Surf. 2007;5(2): 93-107.

16. Hyon JY, Yang HK, Han SB. Dry Eye symptoms may have association with psychological stress in medical students. Eye Contact Lens. 2019;45(5):310-4.

17. Hyon JY, Yang HK, Han SB. Association between dry eye disease and psychological stress among paramedical workers in Korea. Sci Rep. 2019;9(1): 3783.

18. Van Went C, Brasnu E, Hamard P, Baudouin C, Labbé A. The influence of ocular surface diseases in the management of glaucoma. J Fr Ophtalmol. 2011;34(4):230-7.

19. Baudouin C, Renard JP, Nordmann JP, et al. Prevalence and risk factors for ocular surface disease among patients treated over the long term for glaucoma or ocular hypertension. Eur J Ophthalmol. 2013;23(1):47-54.

20. Baudouin C, Labbé A, Liang H, Pauly A, BrignoleBaudouin F. Preservatives in eyedrops: the good, the bad and the ugly. Prog Retin Eye Res. 2010;29(4):312-34.
21. Vaede D, Baudouin C, Warnet JM, Brignole-Baudouin F. Preservatives in eye drops: toward awareness of their toxicity. J Fr Ophtalmol. 2010;33(7): 505-24.

22. Sharma A, Hindman HB. Aging: a predisposition to dry eyes. J Ophthalmol. 2014;2014:781683.

23. Fechtner RD, Godfrey DG, Budenz D, et al. Prevalence of ocular complaints in patients with glaucoma using topical intraocular pressure-lowering medications. Cornea. 2010;29(6):618-21.

24. Najafi L, Malek M, Valojerdi AE, et al. Dry eye and its correlation to diabetes microvascular complications in people with type 2 diabetes mellitus. J Diabetes Complic. 2013;27(5):459-62.

25. Zhang X, Zhao L, Deng S, Sun X, Wang N. dry eye syndrome in patients with diabetes mellitus: prevalence, etiology, and clinical characteristics. J Ophthalmol. 2016;2016:8201053.

26. Mastrota KM. Impact of floppy eyelid syndrome in ocular surface and dry eye disease. Optom Vis Sci. 2008;85(9):814-6.

27. Giannaccare G, Bernabei F, Pellegrini $M$, et al. Eyelid metrics assessment in patients with chronic ocular graft versus-host disease. Ocul Surf. 2019;17(1):98-103.

28. Jaacks LM, Vandevijvere S, Pan A, et al. The obesity transition: stages of the global epidemic. Lancet Diabetes Endocrinol. 2019;7(3):231-40.

29. Pan Z, Mølhave L, Kjaergaard SK. Effects on eyes and nose in humans after experimental exposure to airborne office dust. Indoor Air. 2000;10(4):237-45. 